\title{
Transfer of the symbiotic plasmid from Rhizobium leguminosarum biovar trifolii to Agrobacterium tumefaciens
}

\author{
Mikiko Abe, ${ }^{*}$ Ryoichi Kawamura, Shiro Higashi, Seiichiro Mori, \\ Motoyoshi Shibata, and Toshiki Uchiumi \\ Department of Chemistry and BioScience, Faculty of Science, \\ Kagoshima University, Kagoshima 890-0065, Japan
}

(Received March 17, 1997; Accepted February 27, 1998)

\begin{abstract}
This study examined the symbiotic properties of Agrobacterium transconjugants isolated by transferring a Tn5-mob-marked derivative of the $315 \mathrm{~kb}$ megaplasmid pRt4Sa from Rhizobium leguminosarum bv. trifolii $4 \mathrm{~S}$ (wild-type strain) to Agrobacterium tumefaciens A136 as the recipient. The genetic characteristics of the AT4S transconjugant strains were ascertained by random amplified polymorphic DNA (RAPD) analyses and Southern hybridization using Tn5-mob and nod genes as probes. Several of these AT4S transconjugants carrying pRt4Sa were able to nodulate roots of the normal legume host, white clover. In addition, some AT4S transconjugant strains were able to induce nodules on other leguminous plants, including alfalfa and hairy vetch. A characteristic bacteroid differentiation was observed in clover and alfalfa nodules induced by the AT4S-series strains, although nitrogen-fixing activity (acetylene reduction) was not found. Furthermore, strain H1R1, obtained by retracing transfer of the pRt4Sa::Tn5-mob from strain AT4Sa to strain H1 (pRt4Sa cured derivative of $4 \mathrm{~S}$ ), induced $\mathrm{Fix}^{+}$nodules on clover roots. These results indicate the evidence that only nod genes can be expressed in the Agrobacterium background.
\end{abstract}

Key Words_Agrobacterium tumefaciens; bacteroid differentiation; RAPD; Rhizobium leguminosarum bv. trifolii; symbiotic plasmid; Tn5-mob; wide host range.

Bacteria belonging to Rhizobiaceae display the ability to infect and nodulate their leguminous host plants. The obvious biological activity of Rhizobium in the formed nodules is its ability to fix atmospheric nitrogen into ammonia, which is subsequently assimilated into amino acids as nutrients for the host plants. Infection and nodulation only occur with host-specific combinations of the rhizobial and host plant species. For example, the specific hosts for $R$. leguminosarum bv. trifolii and Bradyrhizobium japonicum are clover and soybean, respectively. A whole series of reactions resulting in nodulation and nitrogen fixation are controlled by nod and nif genes, respectively, in the bacterial symbiont.

Agrobacterium is a phytopathogen that causes crown gall disease on a wide variety of dicotyledonous plants. It can also induce tumors on certain monocots and gymnosperms. The infection process of $A$. tumefaciens is rather complex, involving a number of

\footnotetext{
${ }^{*}$ Address reprint requests to: Dr. Mikiko Abe, Department of Chemistry and BioScience, Faculty of Science, Kagoshima University, 1-21-35 Korimoto, Kagoshima 890-0065, Japan.
}

chemical signal substances elicited by both the pathogen and host plant. Agrobacterium infection is commenced when the bacterial virulent (vir) genes located on its Ti plasmid are induced and expressed by certain phenolic compounds secreted from the wounded site of the plant. Agrobacteria adsorb to the plant cells and transfer part of their Ti plasmid (pTi), called the transferring (T)-DNA, to the chromosome DNA of the host plant cell (Watson et al., 1975).

The taxonomical relationship between root nodule bacteria (Rhizobium) and Agrobacterium is known to be very close (Sawada et al., 1993). The first successful transfer of nodulating ability in Agrobacterium was achieved by transfer of the symbiotic plasmid (pSym) from $R$. leguminosarum bv. trifolii to a pTi-cured $A$. tumefaciens strain (Hooykaas et al., 1982). We hypothesized that the extension of the host range of $R h i-$ zobium would occur when rhizobial nodulation and nitrogen-fixing abilities were transferred to Agrobacterium. In this experiment, the transfer of the symbiotic plasmid (pRt4Sa) of $R$. leguminosarum bv. trifolii $4 \mathrm{~S}$ $\left(\mathrm{Nod}^{+}, \mathrm{Fix}^{+}\right)$to $A$. tumefaciens A136 (Ti-plasmidcured strain) was performed. We report here the pos- 
Table 1. Bacterial strains and plasmids.

\begin{tabular}{|c|c|c|}
\hline Strains and plasmids & Relevant characteristics & References \\
\hline \multicolumn{3}{|c|}{ Rhizobium leguminosarum bv. trifolii } \\
\hline $4 S$ & Wild type, $\mathrm{Hac}^{+}, \operatorname{Inf}^{+}, \mathrm{Nod}^{+}, \mathrm{Fix}^{+}$ & Higashi and Abe (1980) \\
\hline $4 S 5$ & 4S carrying pRt4Sa::Tn5-mob, $\mathrm{Hac}^{+}, \mathrm{Inf}^{+}, \mathrm{Nod}^{+}, \mathrm{Fix}^{+}, \mathrm{Km}^{r}$ & This study \\
\hline $\mathrm{H} 1$ & pSym-cured derivative of $4 \mathrm{~S}, \mathrm{Hac}^{-}, \mathrm{Inf}^{-}, \mathrm{Nod}^{-}, \mathrm{Fix}^{-}$ & Higashi et al. (1983) \\
\hline H1R1 & $\mathrm{H} 1$ carrying pRt4Sa::Tn5-mob, $\mathrm{Hac}^{+}, \operatorname{Inf}^{+}, \mathrm{Nod}^{+}, \mathrm{Fix}^{+}$ & This study \\
\hline \multicolumn{3}{|c|}{ Agrobacterium tumefaciens } \\
\hline A136 & pTi-cured derivative of $\mathrm{C} 58, \mathrm{Rifr}^{r}, \mathrm{Onc}^{-}$ & Watson et al. (1975) \\
\hline AT4S-series & A136 carrying pRt4Sa::Tn5 from $4 \mathrm{~S} 5, \mathrm{Hac}^{+}, \mathrm{Inf}^{+}, \mathrm{Nod}^{+}, \mathrm{Rif}^{r}, \mathrm{Km}^{r}$ & This study \\
\hline \multicolumn{3}{|l|}{ Escherichia coli } \\
\hline S17-1(pSUP5011) & Donor of Tn5-mob, $\mathrm{Km}^{r}, \mathrm{Nm}^{\mathrm{r}}$, $\mathrm{Sm}^{\mathrm{r}}$ thi, pro & Simon (1984) \\
\hline MM294(pRK2013) & Helper for conjugation, $\mathrm{Km}^{\mathrm{r}}$, thi, pro & Figurski and Helinski (1979) \\
\hline HB101(pC4S8) & HB101 carrying pC4S8, $\mathrm{Tc}^{r}$ & This study \\
\hline \multicolumn{3}{|l|}{ Plasmid } \\
\hline $\mathrm{pRt} 4 \mathrm{Sa}$ & pSym of $4 S, 315 \mathrm{~kb}$ & Higashi et al. (1983) \\
\hline pRt4Sa::Tn5-mob & pRt4Sa containing Tn5-mob, $\mathrm{Km}^{r}$ & This study \\
\hline pSUP5011 & Derivative of $\mathrm{pBR} 325$ carrying Tn5-mob, $\mathrm{Km}^{r}, \mathrm{Nm}^{r}, \mathrm{Ap}^{r}$ & Simon (1984) \\
\hline pRK2013 & Helper plasmid, $\mathrm{Km}^{\mathrm{r}}$ & Figurski and Helinski (1979) \\
\hline $\mathrm{pC} 4 \mathrm{~S} 8$ & pLAFR1 carrying $17.75 \mathrm{~kb}$ nod region of $\mathrm{pRt} 4 \mathrm{Sa}, \mathrm{Tc}^{r}$ & This study \\
\hline pLAFR1 & Wide host range costramid & Friedman et al. (1982) \\
\hline
\end{tabular}

Hac, root hair curling; Inf, infection thread formation; Nod, nodulation; Fix, nitrogen fixation; Onc, oncogeny; Km, kanamycin; Rif, rifampicin; $\mathrm{Nm}$, neomycin; Sm, streptomycin; Tc, tetracycline; Ap, ampicillin.

sibility of controlling megaplasmid transfer, and the expansion of host range exhibited by isolated transconjugants.

\section{Materials and Methods}

Bacterial strains and plasmids. Strains are shown in Table 1. R. leguminosarum bv. trifolii $4 S$ is a wildtype strain containing 3 megaplasmids (pRt4Sa, pRt4Sb, and pRt4Sc). pRt4Sa (315 kb) is the symbiotic plasmid (Higashi et al., 1983). Strain 4S can nodulate clovers but not alfalfa or vetch. $A$. tumefaciens A136 is an avirulent, Ti-plasmid-cured derivative of strain C58 (Watson et al., 1975). The $17.75 \mathrm{~kb}$ nodgene region of strain $4 S$ was cloned into the broad host range vector plasmid pLAFR1 (Friedman et al., 1982 ) at its EcoRI site. The resulting plasmid was referred as pC4S8, which was used as a probe in Southern hybridization to confirm the transfer of pRt4Sa in the Agrobacterium transconjugants.

Media and culturing conditions. Rhizobial strains were generally maintained on yeast extract mannitol (YM) medium (Keele et al., 1969). For DNA isolation and bacterial mating, polypeptone and yeast extract (TY) medium (Beringer, 1974) were used. For selection of the Rhizobium transconjugants, the minimal medium (Sherwood, 1970) was prepared as follows: sodium succinate, $1.35 \mathrm{~g}$; sodium glutamate, $1.1 \mathrm{~g}$; $\mathrm{K}_{2} \mathrm{HPO}_{4}, 0.22 \mathrm{~g} ; \mathrm{MgSO}_{4}, 0.1 \mathrm{~g} ; \mathrm{CaCl}_{2}, 0.44 \mathrm{~g} ; \mathrm{FeCl}_{3}$, $0.22 \mathrm{~g}$; thiamine $\mathrm{HCl}, 0.1 \mathrm{mg}$; biotin, $0.2 \mathrm{mg}$, in $1 \mathrm{l}, \mathrm{pH}$ 6.8. E. coli and Agrobacterium strains were grown on LB medium (Sambrook et al., 1989) supplemented with appropriate antibiotics, kanamycin $(20 \mu \mathrm{g} / \mathrm{ml})$ for E. coli and rifampicin $(50 \mu \mathrm{g} / \mathrm{ml})$ for Agrobacterium. Rhizobial strains containing Tn5-mob were cultured in media supplemented with kanamycin $(100 \mu \mathrm{g} / \mathrm{ml})$. Agrobacterium transconjugants were cultured on LB medium containing both rifampicin $(50 \mu \mathrm{g} / \mathrm{ml})$ and kanamycin $(100 \mu \mathrm{g} / \mathrm{ml})$.

Bacterial mating procedure. Two mating procedures are shown in Fig. 1. The first mating was performed between E. coli S17-1(pSUP5011) (Simon, 1984) and $R$. leguminosarum bv. trifolii 4S. Both strains ( $10^{8}$ cells each) were mixed in a $1 \mathrm{ml}$ suspension in an Eppendorf tube and incubated for $8 \mathrm{~h}$ at $27^{\circ} \mathrm{C}$. Transconjugants were screened on minimal medium plates containing kanamycin $(100 \mu \mathrm{g} / \mathrm{ml})$ (Jagadish and Szalay, 1984). Kanamycin-resistant colonies were picked up randomly. Each colony was tested for nodulation on white clover and confirmed for Tn5-mob insertion on pRt4Sa by Southern hybridization. One strain was selected and named strain 4S5 for use in subsequent transformation. The second mating was performed among E. coli MM294 (pRK2013 containing the tra gene from pRK2) (Figurski and Helinski, 1979), Tn5-mob-inserted Rhizobium strain 4S5 and pTi-cured Agrobacterium strain A136 (ca. $10^{9} \mathrm{cell} / \mathrm{s} / \mathrm{ml}$ of each). Each bacterial culture was mixed in $100 \mu \mathrm{l}$ at a ratio of $1: 2: 2$ by volume. After centrifugation at $10,000 \times g$ for $1 \mathrm{~min}$, the cell pellet was rinsed and suspended in $200 \mu$ l of sterilized distilled water. Fifty microliters of this bacterial suspension was transferred to a membrane filter (pore size $0.45 \mu \mathrm{m}$ ) on a TY agar plate without antibiotics 


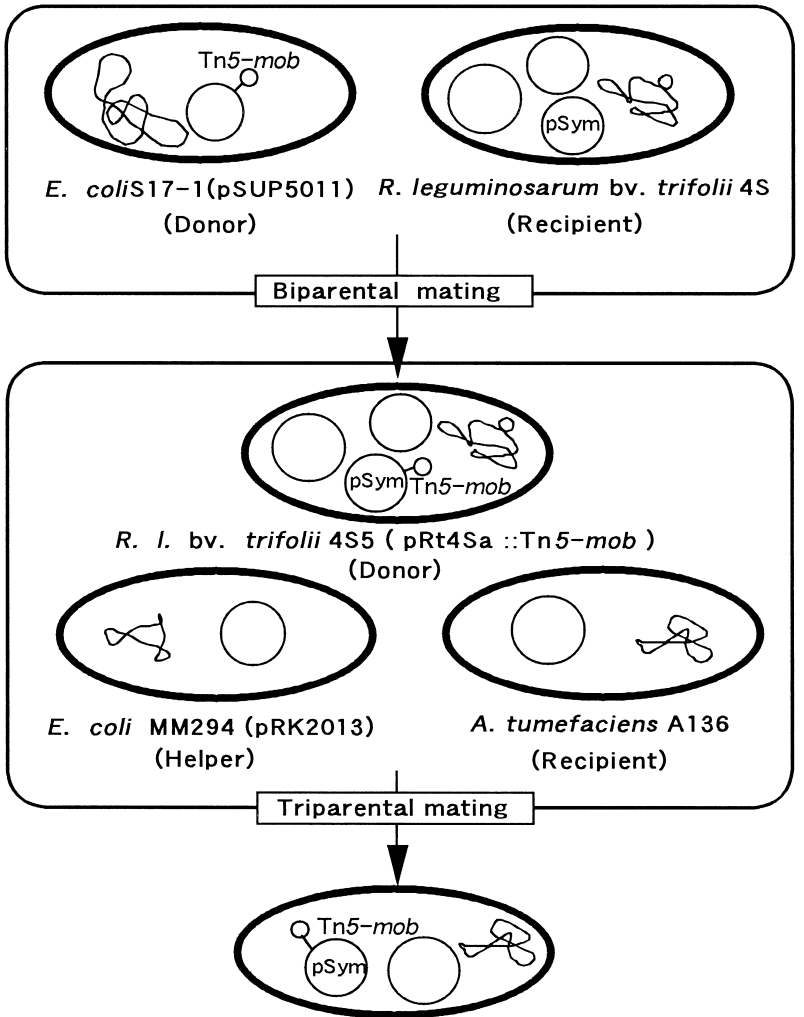

A. tumefaciens AT4S-series (pRt4Sa ::Tn 5-mob)

Fig. 1. The mating procedure between strains $4 \mathrm{~S}, 4 \mathrm{~S} 5$, and A136.

and cultured overnight at $27^{\circ} \mathrm{C}$. Proliferated cells on the membrane filter were suspended in $1 \mathrm{ml}$ sterilized distilled water, spread on LB plates containing kanamycin at $100 \mu \mathrm{g} / \mathrm{ml}$ and rifampicin at $50 \mu \mathrm{g} / \mathrm{ml}$, and cultured for $4-5$ days at $27^{\circ} \mathrm{C}$. The proliferated colonies were mixed and inoculated on clover seedlings. After 30 days of incubation, bacteria were reisolated from formed nodules on antibiotic-containing LB plates as reported previously (Uchiumi et al., 1995). The reisolated strains were referred to as the AT4S series.

DNA isolation and analyses. Total DNAs were isolated from Rhizobium and Agrobacterium by the modified method of Casse et al. (1979). Plasmid DNA from $E$. coli was isolated according to the method of Birnboim (1983). For Southern hybridization, total DNAs of Rhizobium and Agrobacterium were digested with EcoRI or Hindlll for the detection of nod genes and Tn5-mob, respectively. After electrophoresis in 0.7\% agarose, plasmid DNAs and digested DNA fragments were blotted on nylon 66 filters (NYTRAN NY13N, Schleicher \& Schuell, pore size $0.45 \mu \mathrm{m}$ ) (Reed and Mann, 1985) hybridized with probes for the Tn5-moband nod-gene regions of strain $4 \mathrm{~S}$ ( $\mathrm{pC} 4 \mathrm{~S} 8$ ). For each DNA probe, Tn5-mob was extracted from pSUP5011 by Hindlll digestion, and the nod gene was extracted from $\mathrm{pC} 4 \mathrm{~S} 8$ by EcoRI digestion. Hybridized profiles were visualized with DNA labeling and detection kits (digoxigenin-DIG ELISA and DIG Luminescent, Boehringer Mannheim).

Random amplified polymorphic DNA (RAPD) method and nodC detection of Rhizobium, Agrobacterium and Agrobacterium transconjugants by PCR. Two different PCR oligonucleotide primers were used for the RAPD method (Dye et al., 1995). The sequences were 5'GGTGCGGGAA3' for RAPD1 and 5'GTTTCGCTCC3' for RAPD2. The reactions were performed in $50 \mu \mathrm{l}$ volumes, using $50 \mathrm{ng}$ of bacterial template DNA, $50 \mathrm{pmol}$ of primer nucleotide, and $2.5 \mathrm{U}$ TaKaRa Taq polymerase (Takara Shuzo Co. Ltd., Ohtsu, Japan). The reaction conditions were as follows: $4 \mathrm{~min}$ at $95^{\circ} \mathrm{C}$ for the first denaturation, $1 \mathrm{~min}$ at $95^{\circ} \mathrm{C}, 1 \mathrm{~min}$ at $37^{\circ} \mathrm{C}, 2 \mathrm{~min}$ at $72^{\circ} \mathrm{C}$ for 40 cycles, and $5 \mathrm{~min}$ at $72^{\circ} \mathrm{C}$ for the final extension. For nodC detection, the sequences of the amplification primers were as follows: 251F, AYGTIGTYGAYGAYGGWTC, 566R, AGCCARTACTCCATGTCGATCAA, reported by Ueda et al. (1995); and PCR cycles were $1 \mathrm{~min}$ at $94^{\circ} \mathrm{C}$ for the first denaturation, $30 \mathrm{~s}$ at $94^{\circ} \mathrm{C}, 30 \mathrm{~s}$ at $37^{\circ} \mathrm{C}, 2 \mathrm{~min}$ at $60^{\circ} \mathrm{C}$ for 5 cycles, $30 \mathrm{~s}$ at $94^{\circ} \mathrm{C}, 30 \mathrm{~s}$ at $50^{\circ} \mathrm{C}, 30 \mathrm{~s}$ at $72^{\circ} \mathrm{C}$ for 40 cycles, and $5 \mathrm{~min}$ at $72^{\circ} \mathrm{C}$ for the final extension. The amplifications were performed with a Gene Amp PCR System 2400 (Perkin-Elmer Co., USA). The PCR products were analyzed by $1.0 \%$ agarose gel electrophoresis.

Nodulation and nitrogen fixation test. Infection and nodulation tests of the transconjugants were examined on white clover (Trifolium repens L. Cv. Ladino), alfalfa (Medicago sativa L. cv. Common), hairy vetch (Vicia hirsuta (L.) S. F. Gray), Mung bean (Vigna mungo L.) and soybean (Glycine max (L.) Merrill cv. Peking) (Fahraeus, 1957; Higashi and Abe, 1980). The nitrogen fixation ability of nodules formed on white clover and alfalfa was detected by acetylene-reducing activity (ARA) as described previously (Hardy et al., 1968). Infection threads formed in clover root hairs were observed by light microscopy.

Scanning electron microscopy. Nodules were longitudinally and/or cross-sectioned at the central position, fixed overnight at $4{ }^{\circ} \mathrm{C}$ with $2.5 \%$ glutaraldehyde in $50 \mathrm{~mm}$ Na-cacodylate buffer ( $\mathrm{pH} 6.5)$, and dehydrated with an ethanol series (more than 30 min each). After dehydration in absolute ethanol, nodules were treated twice with tert-butanol (2-methyl-2propanol) and ethanol $(1: 1 \mathrm{v} / \mathrm{v})$ followed by $100 \%$ tert-butanol, and then frozen overnight in a refrigerator. Specimens were dried under reduced pressure, coated with platinum at $15 \mathrm{~nm}$ thickness, and examined by a field-emission scanning electron microscope (4100H, Hitachi Co., Ltd., Tokyo, Japan). 


\section{Results}

In the first step of mating (Fig. 1), insertion of the Tn5-mob from pSUP5011 into the Sym plasmid $\mathrm{pRt} 4 \mathrm{Sa}$ of strain $4 \mathrm{~S}$ was performed. Total DNA extracted from a kanamycin-resistant transconjugant (4S5) was hybridized with the Tn5-mob probe, indicating the presence of the Tn5-mob insertion in the
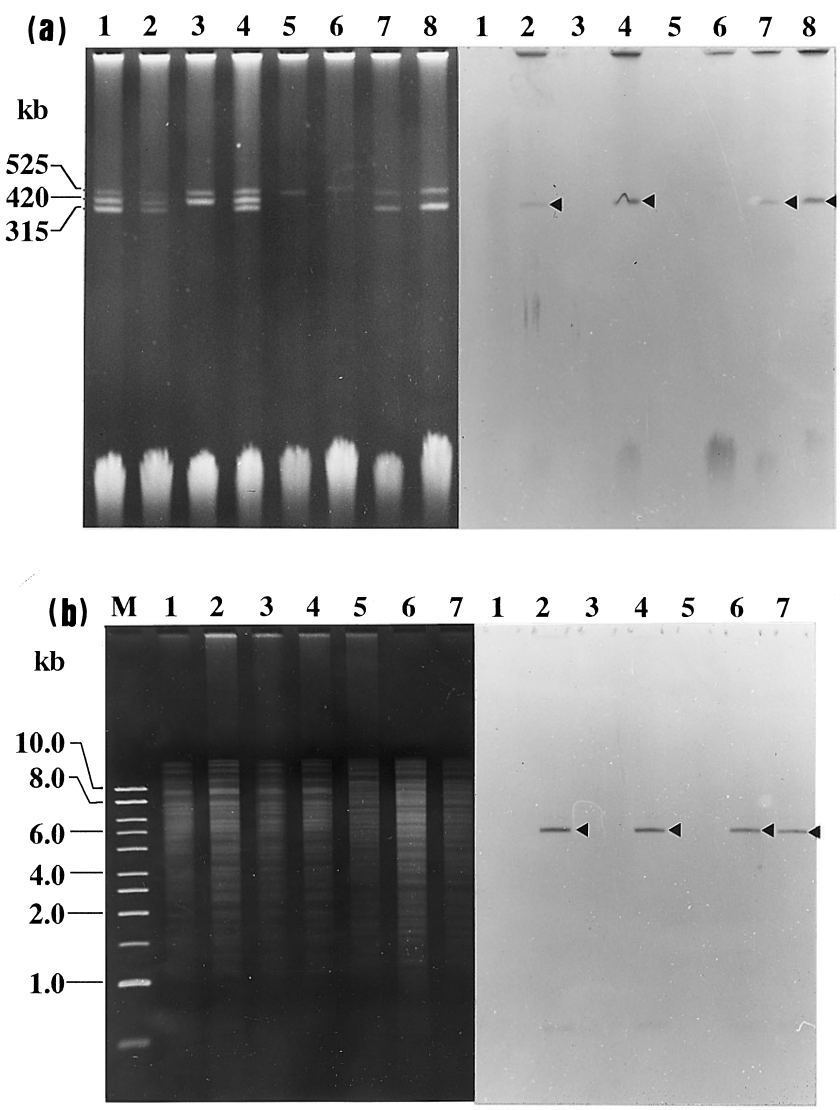

Fig. 2. Southern hybridization profiles of isolated plasmids (a) and Hindlll-digested total DNA (b) from Rhizobium and Agrobacterium transconjugant with Tn5-mob gene as the probe.

Lanes 1-4, Rhizobium strains: 1, 4S; 2, 4S5; 3, H1; 4, H1R1. Lane 5, Agrobacterium tumefaciens A136. Lanes 6-8, Agrobacterium transconjugants: 6, AT4Sa; 7, AT4SB; 8, AT4SG. Lanes 2, 4, 7, 8 show Tn5-mob gene is on a pRt4Sa (Sym plasmid) indicated by arrowheads, but Lane 6 did not exhibit a clear band and hybridized pattern of pRt4Sa (a). The same hybridized band pattern was shown on the Hindlll-digested total DNA fragment, indicated by arrowheads (b).
pRt4Sa (Fig. 2a, b). The transconjugant 4S5 maintained nodulation and nitrogen fixation abilities on white clover (Table 2).

The transfer of pRt4Sa::Tn5-mob $\left(\mathrm{Km}^{\mathrm{r}}\right)$ from strain 4S5 to Agrobacterium tumefaciens A136 (Rifr) using triparental mating with E. coli MM294 (pRK2013) (Fig. 1) resulted in Agrobacterium transconjugants at a transferring frequency of about $10^{-6}$ (per input donor cell). Transconjugant strains were inoculated to white clover seedlings and reisolated from formed nodules to screen the symbiotic plasmid (pRt4Sa)-transferred Agrobacterium. The transferred plasmid was recognized by agarose gel electrophoresis and Southern hybridization using the nod genes of strain $4 \mathrm{~S}$ as the probe (Fig. 3a, b, and c). In strain AT4Sa, plasmids pRt4Sa::Tn5-mob and pRt4Sa could not be detected (Figs. 2a and 3a). However, the existence of both Tn5-mob and nod genes in strain AT4Sa was confirmed on the total DNA blotted filters by Southern hybridization, as well as other AT4S-series strains (Figs. 2b, 3b, and 3c). RAPD analyses of Rhizobium, Agrobacterium and Agrobacterium transconjugant strains (AT4S-series) indicated that strains $\mathrm{H} 1$ and 4S5 exhibited similar band patterns to Rhizobium strain 4S, whereas strains AT4Sa, AT4SB and AT4SG exhibited common band patterns originating from Agrobacterium strain A136 (Fig. 4). The PCR analysis using primers for nodC detection confirmed that all tested AT4S-series strains contained the same fragment size (350 bp) of DNA as found in strains $4 \mathrm{~S}$ and 4S5 (Fig. 5).

The AT4S-series strains were tested for nodule induction and $\mathrm{N}_{2}$ fixation (acetylene reduction) on white clover (Table 2). Nodules were visualized within 6 to 7 days after inoculation with the transconjugant and wild-type strains (Fig. 6A). Strains AT4Sa, AT4SB, AT4SD, AT4SE, and AT4SG induced two to three times more nodules on white clover than did wild-type strain 4S. The nodulation frequency with AT4S-series strain inoculation was more than $90 \%$ as well as strain $4 \mathrm{~S}$ at 10 to 15 days after inoculation (data not shown). Interestingly, strain AT4Sa also nodulated hairy vetch ( $V$. hirsuta) at the 4th week after inoculation, and strain AT4SG nodulated alfalfa ( $M$. sativa) at the 3 rd week after inoculation (Fig. 6B). Nodules on these al-

Table 2. Induction of nodules and their acetylene reduction activity on white clover inoculation with Rhizobium and Agrobacterium. ${ }^{2}$

\begin{tabular}{lccccccccccc}
\hline Activity & $4 \mathrm{~S}$ & 4S5 & $\mathrm{H} 1$ & $\mathrm{H} 1 \mathrm{R} 1$ & AT4Sa & AT4SB & AT4SD & AT4SE & AT4SG & A136 \\
\hline Nodulation $^{b}$ & + & + & - & + & +++ & ++ & ++ & ++ & ++ & - \\
Acetylene reduction $^{c}$ & 0.19 & 0.25 & 0 & 0.37 & 0 & 0 & 0 & 0 & 0 & 0 & 0 \\
\hline
\end{tabular}

${ }^{a}$ Rhizobium strains; 4S, 4S5, H1, H1R1, Agrobacterium strain; A136. Agrobacterium-transconjugant strains; AT4Sa, AT4SB, AT4SD, AT4SE, AT4SG.

${ }^{b}$ For nodulation: Total $20-50$ seedlings were used.,$+<5$ nodules/plant;,$++ 5 \leq 10$ nodules/plant;,$+++ 10<$ nodules/plant.

${ }^{c}$ Acetylene reduction (nm/plant/h)was measured at 50 days after inoculation. 

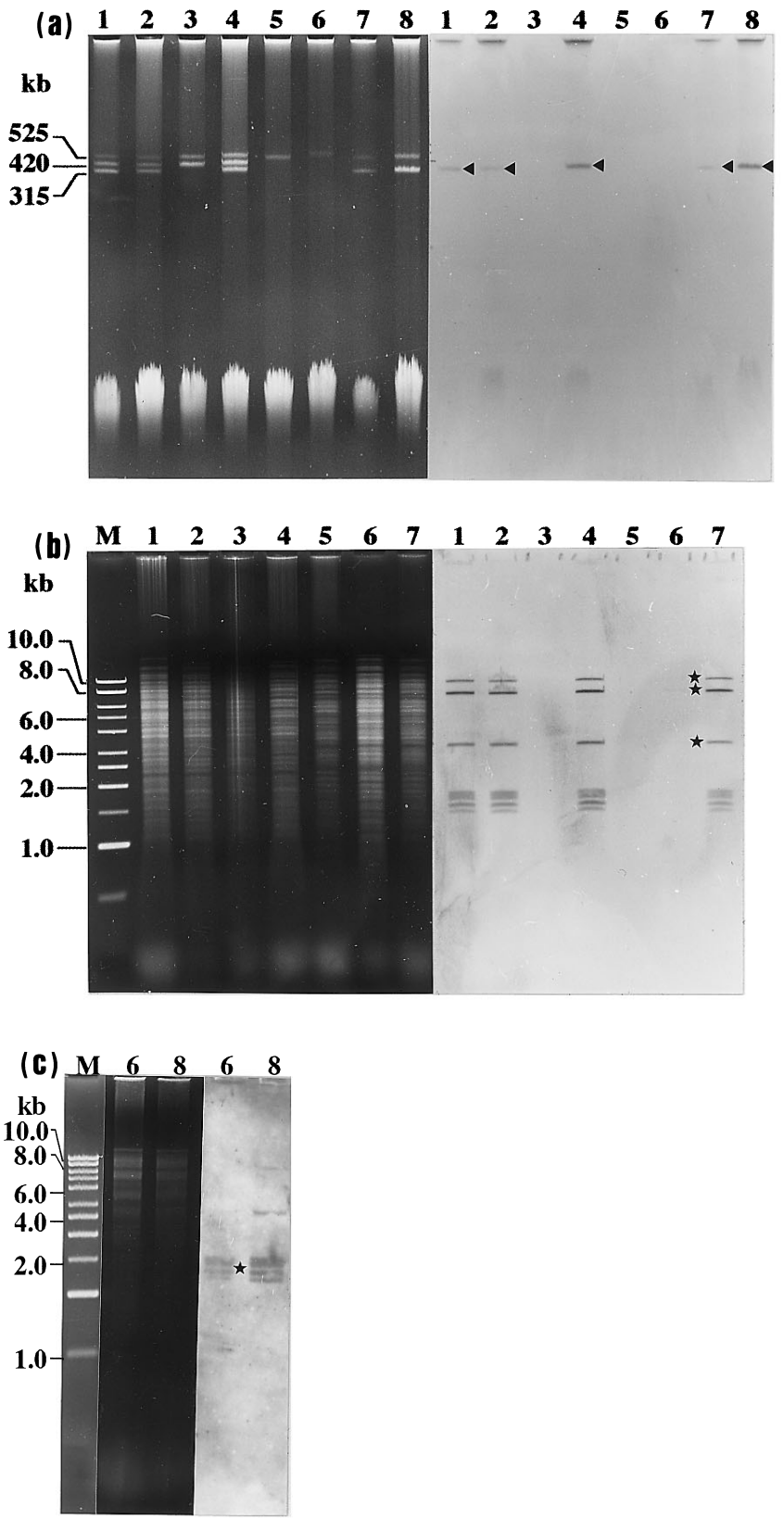

Fig. 3. Southern hybridization profiles of isolated plasmids (a) and EcoRI-digested total DNA (b, c) from Rhizobium and Agrobacterium transconjugants with nod genes as the probe.

Lanes 1-4, Rhizobium strains: 1, 4S; 2, 4S5; 3, H1; 4, H1R1. Lane 5, Agrobacterium tumefaciens A136. Lanes 6-8, Agrobacterium transconjugants: 6, AT4Sa; 7, AT4SB; 8, AT4SG. Lanes 2, 4, 7, 8 show nod genes on a pRt4Sa (Sym plasmid) indicated by arrowheads, but Lane 6 did not exhibit a clear band and hybridized pattern at the pRt4Sa position (a). Several hybridized band profiles were shown on the EcoRl-digested total DNA fragments (b, c). AT4Sa (Lane 6) exhibited very faint hybridized patterns, indicated by stars.

ternate hosts can emerge within 7-10 days after inoculation with the compatible symbiont, Rhizobium (Table 3). Figure 6A shows the nodules formed on
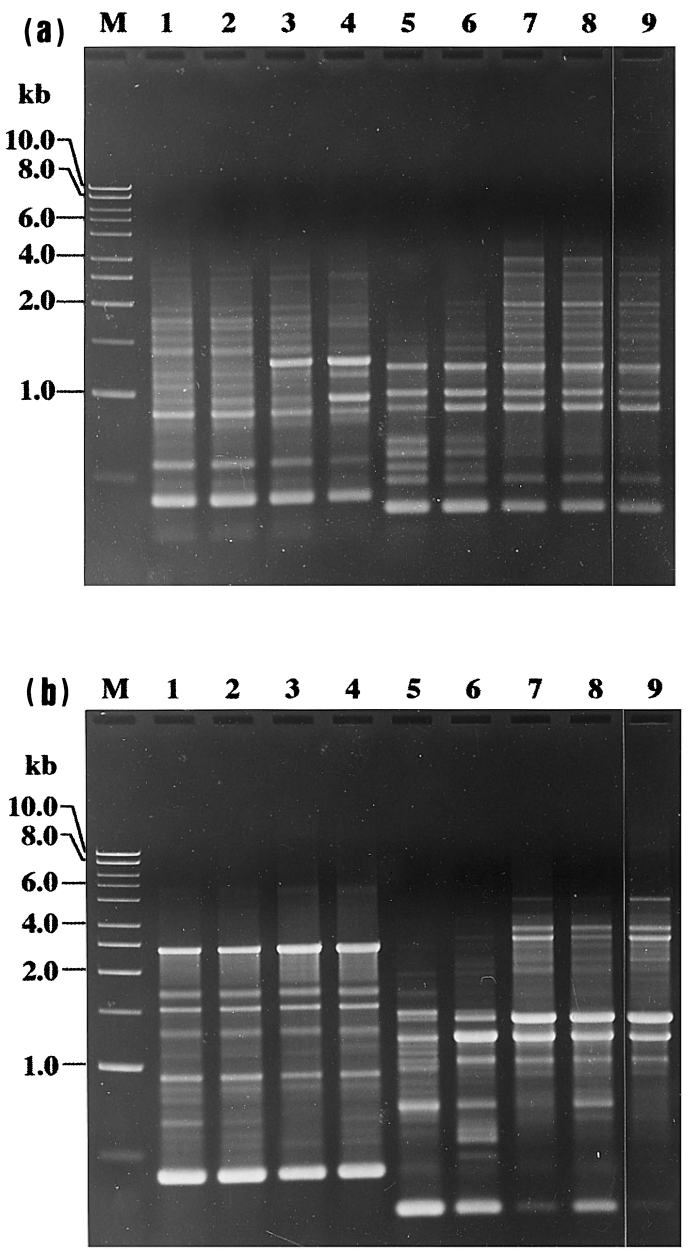

Fig. 4. RAPD analysis of Rhizobium and Agrobacterium transconjugants.

Primers 1 (a) and 2 (b) are listed in Materials and Methods. Lanes 1-4, Rhizobium strains: 1, 4S; 2, 4S5; 3, H1; 4, H1R1. Lane 5, Agrobacterium tumefaciens A136. Lanes 6-9, Agrobacterium transconjugants: 6, AT4Sa; 7, AT4SB; 8, AT4SG; 9, AT4SG $\alpha$ (strain reisolated from an alfalfa nodule formed by AT4SG inoculation).

white clover by inoculation with transconjugant strain AT4SB. A complete infection thread was formed in the curled root hair cell of white clover at the 7th day after inoculation with transconjugant strain AT4SG (Fig. $6 \mathrm{C})$. The clover nodules formed after inoculation with strain 4S and the AT4S strain series contained clubshaped bacteroid cells (Fig. 7).

The nodules formed on alfalfa roots inoculated with transconjugant strain AT4SG were also examined by SEM. These nodules contained bacteria exhibiting the characteristic Y-shaped morphological change of bacteria as was found in alfalfa nodules induced by $R$. meliloti strain 1021 (Fig. 8).

Triparental mating between strain AT4Sa (donor) and strain $\mathrm{H} 1$ (recipient) was also performed. One of the resulting transconjugant strains derived from this cross was referred to as strain H1R1. The retraced 


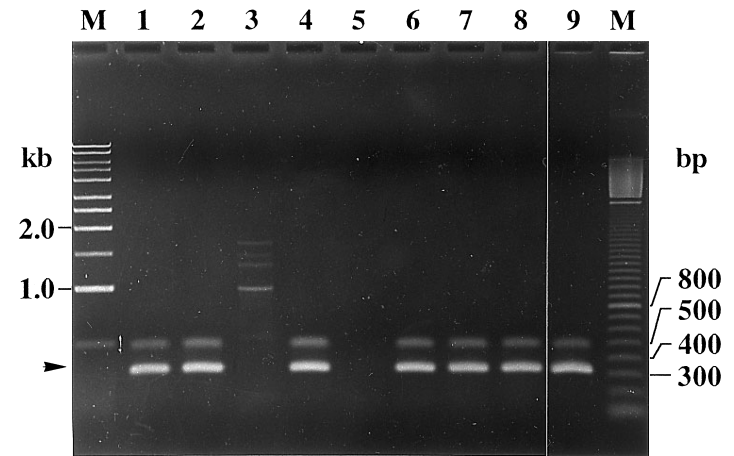

Fig. 5. PCR patterns of nodC region from Rhizobium and Agrobacterium-transconjugant DNAs.

Amplified nodC band is indicated by an arrowhead. Lanes 1-4, Rhizobium strains: 1, 4S; 2, 4S5; 3, H1; 4, H1R1. Lane 5, Agrobacterium tumefaciens A136. Lanes 6-9, Agrobacterium transconjugants: 6, AT4Sa; 7, AT4SB; 8, AT4SG; 9, AT4SG $\alpha$ (strain isolated from alfalfa nodule formed by AT4SG inoculation).

pRt4Sa::Tn5-mob from strain AT4Sa to $\mathrm{H} 1$ was confirmed by the existence of plasmid profiles of pRt4Sa and Southern hybridization probed with Tn5- mob (Fig. 2) and nod genes (Fig. 3). The RAPD pattern of strain H1R1 also indicated the same profiles as in Rhizobium strains 4S, $\mathrm{H} 1$ and 4S5 (Fig. 4b). The white clover nodules formed by strain H1R1 had levels of nitrogen fixation activity which were similar or even higher than in nodules induced by wild-type strain 4S (Table 2). This result is proof that Agrobacteriumtransconjugant strain AT4Sa possess functional nod, nif and fix genes derived from pRt4Sa.

\section{Discussion}

The exchange of infection signals between rhizobia and host plants is well known (Higashi, 1993). Nod factors (lipochitin-oligosaccharides) are synthesized and secreted from the Rhizobium cell as a result of nod-gene expression. These products have been recognized as major mediators of host specificity in root hair deformation and nodule primordia induction (Spaink, 1995). In this experiment, typical morphological changes of root hair, such as curling, branching and infection thread formation in the root hair cell, and nodule formation were also confirmed with AT4S-series inoculated clover root. These observations proclaim that nod-gene expression of Agrobacteriumtransconjugant cells and plant signal response may occur as normally as wild-type strain $4 \mathrm{~S}$.

Truchet et al. (1984) and Wong et al. (1983) have reported the transfer of rhizobial Sym plasmid to $A$. tumefaciens, and tested their symbiotic performance in the appropriate host plant. However, no nitrogen-fixing nodules have been obtained in either case; the results have shown atypical bacterial penetration with-
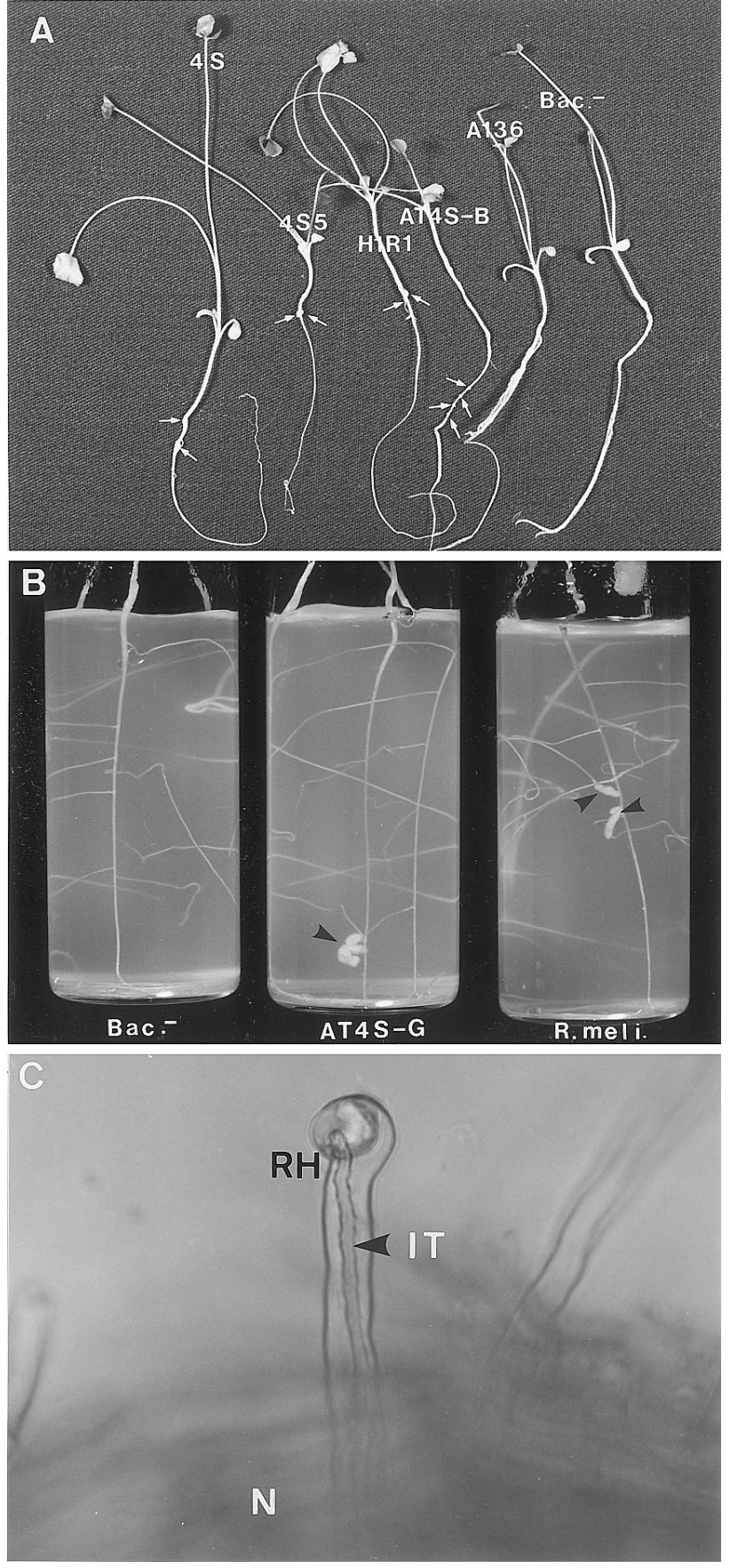

Fig. 6. Root nodules of clover (A) and alfalfa (B) induced by inoculation with Rhizobium and Agrobacterium transconjugants.

Nodules are indicated by arrows. 4S, 4S5, H1R1, R. I. bv. trifoli strains; R. meli., R. meliloti 1021; AT4SB, AT4SG, Agrobacterium transconjugants; A136, pTi cured Agrobacterium tumefaciens; $\mathrm{Bac}^{-}$, no inoculation. Clover and alfalfa plants were photographed at the 30th day after inoculation. Infection thread (arrowhead) in clover root hair inoculated with strain AT4SG (C). IT, infection thread; $\mathrm{RH}$, root hair; $\mathrm{N}$, nodule.

out infection threads and no intracellular bacteria in formed nodules. In contrast, detailed microscopical studies revealed that infection threads were formed in 

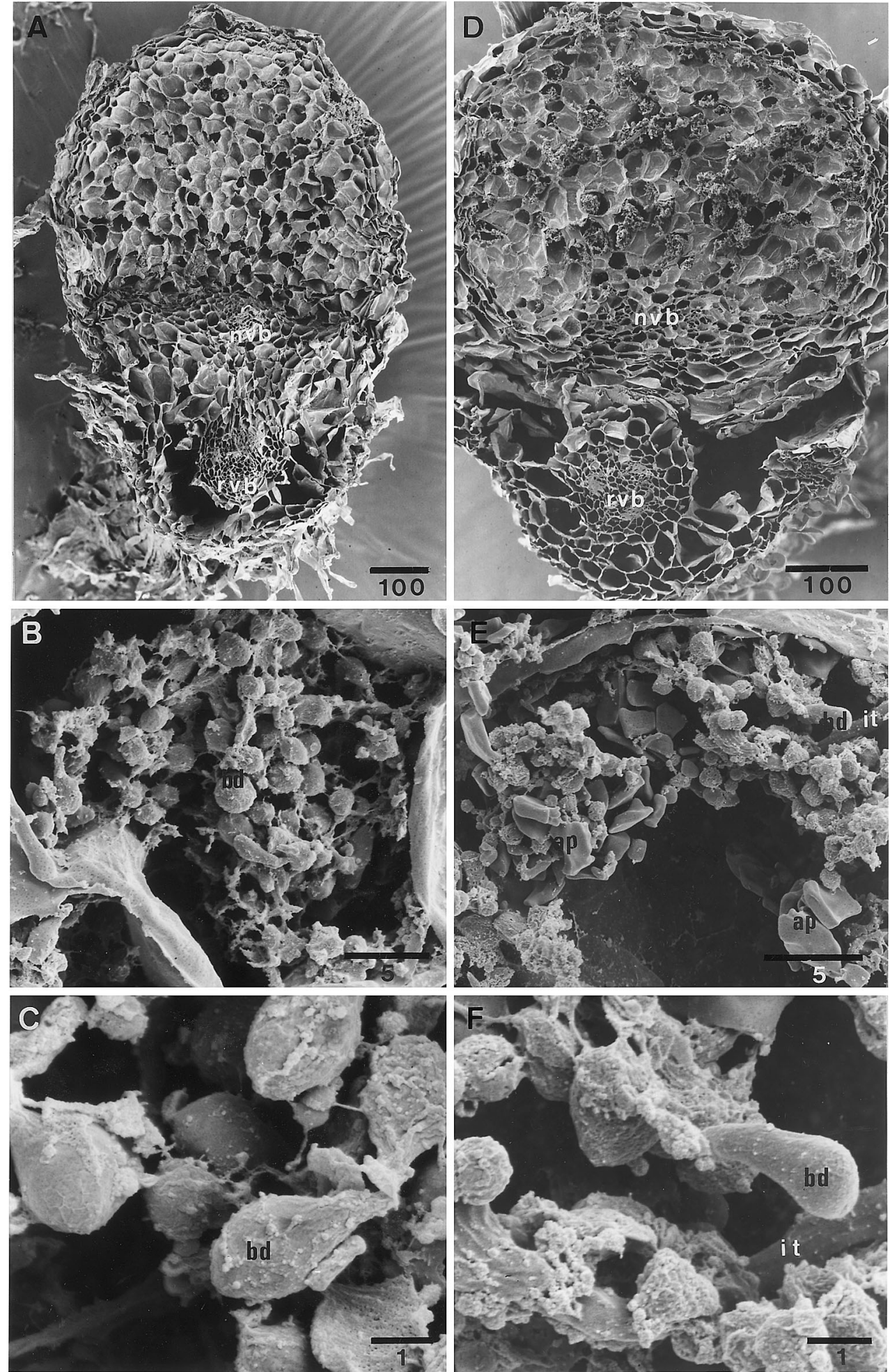

Fig. 7. Scanning electron micrographs of clover nodules induced by Rhizobium strain 4S (A, B, C) and Agrobacterium transconjugant strain AT4SG (D, E, F).

nvb, nodule vascular bundle; rvb, root vascular bundle; bd, bacteroid; ap, amyloplast; it, infection thread. Scale bars in $\mu \mathrm{m}$. 

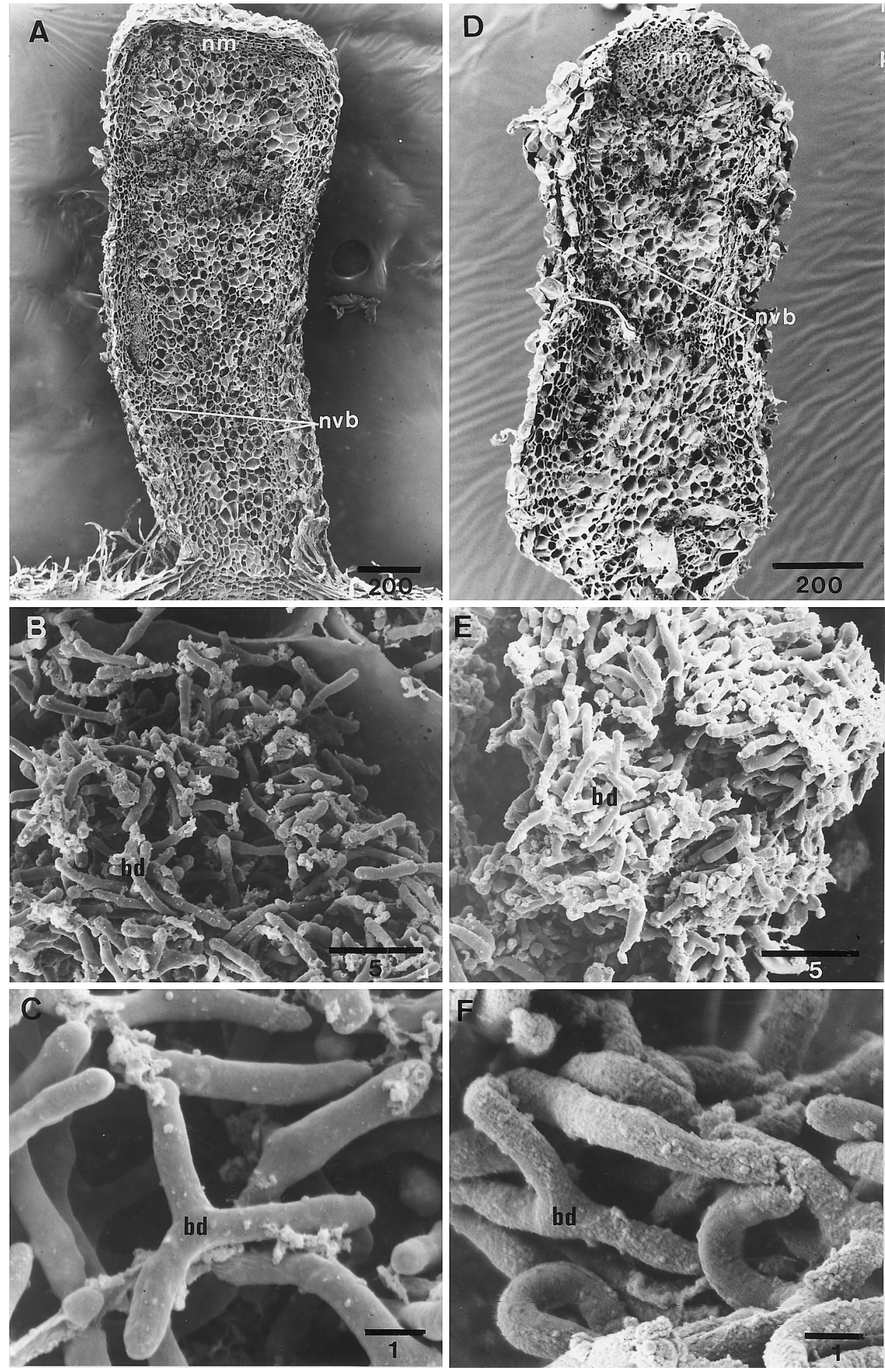

Fig. 8. Scanning electron micrographs of alfalfa nodules induced by Rhizobium meliloti 1021 (A, B, C) and Agrobacterium transconjugant strain AT4SG (D, E, F).

$\mathrm{nm}$, nodule meristem; nvb, nodule vascular bundle; bd, bacteroid. Scale bars in $\mu \mathrm{m}$. 
Table 3. Nodulation on five kinds of leguminous plant with Rhizobium and Agrobacterium-transconjugant inoculation.

\begin{tabular}{llllllllll}
\hline \multirow{2}{*}{ Plants } & \multicolumn{10}{c}{ Strains } \\
\cline { 2 - 10 } & $4 S$ & 4S5 & AT4Sa & AT4SB & AT4SG & A136 & H1 & H1R1 & Cont. \\
\hline Trifolium repens & + & + & + & + & + & - & - & + & - \\
Medicago sativa & - & - & - & - & + & - & - & n.d. & - \\
Vicia hirsuta & - & - & + & - & - & - & - & n.d. & - \\
Vigna mungo & - & - & - & - & - & - & - & n.d. & - \\
Glycine max & - & - & - & - & - & - & - & n.d. & - \\
\hline
\end{tabular}

For nodulation, 20 seedlings of $T$. repens and $M$. sativa, 10 seedlings of $V$. hirsuta, $V$. mungo and $G$. max were tested. n.d., not determined.

root hairs of white clover inoculated with pTi-cured Agrobacterium transconjugants containing pSym from R. leguminosarum bv. trifolii (Dazzo, unpublished data).

We confirmed, in this report, the mobilization of megaplasmid (pRt4Sa, $315 \mathrm{~kb}$ ) by insertion of the Tn5-mob gene, and the transferred plasmid was conservatively maintained in the recipient Agrobacterium cell accompanying normal infection thread and nodule formation abilities (Fig. 6). Hirsch et al. (1984) reported that Agrobacterium transconjugants isolated by transfer of the symbiotic plasmid from $R$. meliloti induced nodule structures on alfalfa roots, but neither peribacteroid membrane nor bacteroid differentiation were observed. In the root nodule cells of clover and alfalfa induced by strain AT4SG, typical morphological changes and enlargement of the symbiotic bacteria, such as club and $Y$ shapes, were observed (Figs. 7, 8). This suggests that the rhizobial nodulation genes on pRt4Sa could be normally expressed in an Agrobacterium cell background and that bacteroid differentiation has taken place.

The extended host range of strain AT4SG was confirmed by Southern hybridization (Figs. 2, 3), while in the RAPD pattern of the reisolated bacteria from the alfalfa nodule formed by strain AT4SG, indicated as strain AT4SG $\alpha$, no typical difference could be identified in the major band pattern as strains AT4SB and AT4SG (Fig. 4). There is no clear answer why only two strains, AT4Sa and AT4SG, expressed this host range extension (Table 3 ). The creation of a wide host-range strains of root nodule bacteria by using rhizobial Sym plasmid transfer to Agrobacterium was also attempted by several research groups. Hooykaas et al. (1982) reported that characteristic spherical root nodules were formed on bean by the transconjugated strains of $R$. trifolii or $A$. tumefaciens introduced to the Sym plasmid of $R$. phaseoli, but no nitrogen fixation could be detected. However, Martinez et al. (1987) reported that the Agrobacterium transconjugants harboring the $410 \mathrm{~kb}$ plasmid of $R$. phaseoli formed effective nodules on Phaseolus vulgaris and Leucaena escu- lenta. They showed that the $410 \mathrm{~kb}$ plasmids of $R$. phaseoli were expressed in $A$. tumefaciens cell background and directed the formation of effective nodules. Novikova and Safronova (1992) had also reported the transfer of pSym of $R$. galegae to $A$. radiobacter, where the transconjugants formed effective nodules on Medicago sativa.

At present, no nitrogen-fixing activity has been found with the nodules induced by the AT4S-series strains on either clover or alfalfa (Table 2), although bacteroid differentiation in the nodule cells was observed in both hosts (Figs. 7, 8). In the strain AT4Sa, transferred plasmid ( $\mathrm{pRt} 4 \mathrm{Sa}$ ) could not be detected (Fig. 3a), but the existence of a nod-gene region derived from strain $4 \mathrm{~S}$ was confirmed by Southern hybridization of EcoRI-digested total DNA. Moreover, the transfer of pRt4Sa::Tn5-mob from strain AT4Sa to pSym-cured strain $\mathrm{H} 1$ has been confirmed as a plasmid band in the retraced strain H1R1 (Fig. 3a). For the moment, there is no evidence on how to present the pRt4Sa::Tn5-mob in the strain AT4Sa, whereas the retraced strain $\mathrm{H} 1 \mathrm{R} 1$ displayed normal nodulation and nitrogen-fixing ability (Table 2). We predict that there must be some regulation system to express the nitrogen fixation genes, which may only be activated in certain Rhizobium cell backgrounds. The retraced transconjugants exemplified by strain $\mathrm{H} 1 \mathrm{R} 1$ have a bright prospect of further analyses on the early stage of the infection process and nitrogen-fixing mechanisms induced by nod- or nif-gene expressions.

We are grateful to Prof. Dr. Frank B. Dazzo, Michigan State University, USA, for his critical reading and helpful advice regarding this manuscript. A part of this work was supported by a grant for the "Research for the Future" program, JSPS-RFTF96L00601, The Japan Society for the Promotion of Science.

\section{References}

Beringer, J. E. (1974) R factor transfer in Rhizobium leguminosarum. J. Gen. Microbiol., 84, 188-198.

Birnboim, H. C. (1983) A rapid alkaline extraction method for isolation of plasmid DNA. Methods Enzymol., 100, 234-254.

Casse, F., Boucher, C., Julliot, J. S., Michel, M., and Denarie, J. 
(1979) Identification and characterization of large plasmid in Rhizobium meliloti using agarose gel electrophoresis. J. Gen. Microbiol., 113, 229-242.

Dye, M., Skot, L., Mytton, L. R., Harrison, S. P., Dooley, J. J., and Cresswell, A. (1995) A study of Rhizobium leguminosarum biovar trifolii populations from soil extracts using randomly amplified polymorphic DNA profiles. Can. J. Microbiol., 41, 336-344.

Fahraeus, G. M. (1957) The infection of clover root hair by nodule bacteria studied by a single glass slide technique. J. Gen. Microbiol., 16, 374-381.

Figurski, D. H. and Helinski, D. R. (1979) Replication of an origincontaining derivative of plasmid RK2 dependent on a plasmid function provided in Trans. Proc. Natl. Acad. Sci. U.S.A., 76, 1648-1652.

Friedman, A. M., Long, S. R., Brown, S. E., Buikema, W. J., and Ausubel, F. M. (1982) Construction of a broad host range cosmid cloning vector and its use in the genetic analysis of Rhizobium mutants. Gene, 18, 289-296.

Hardy, R. W. F., Holsten, R. D., Jackson, E. K., and Burns, R. C. (1968) The acetylene-ethylene assay for $\mathrm{N}_{2}$ fixation: Laboratory and field evaluation. Plant Physiol., 43, 1185-1207.

Higashi, S. (1993) (Brady)Rhizobium-plant communications involved in infection and nodulation. J. Plant Res., 106, 201-211.

Higashi, S. and Abe, M. (1980) Promotion of infection thread formation by substances from Rhizobium trifolii. J. Appl. Environ. Microbiol., 39, 297-301.

Higashi, S., Uchiumi, T., and Abe, M. (1983) Elimination of Rhizobium infectivity by temperature treatment. J. Gen. Appl. Microbiol., 29, 281-285.

Hirsch, A. M., Wilson, K. J., Jones, J. D., Bang, M., Walker, V. V., and Ausubel, F. M. (1984) Rhizobium meliloti nodulation genes allow Agrobacterium tumefaciens and Escherichia coli to form pseudonodules on alfalfa. J. Bacteriol., 158, 1133-1143.

Hooykaas, P. J. J., Snijdewint, F. G. M., and Schilperoort, R. A. (1982) Identification of the Sym plasmid of Rhizobium leguminosarum strain 1001 and its transfer to and expression in other rhizobia and Agrobacterium tumefaciens. Plasmid, 8, 73-82.

Jagadish, M. N. and Szalay, A. A. (1984) Directed transposon Tn5 mutagenesis and complementation in slow-growing, broad host range cowpea Rhizobium. Mol. Gen. Genet., 196, 290-300.

Keele, B. B., Hamilton, P. B., and Elkan, G. H. (1969) Glucose catabolism in Rhizobium japonicum. J. Bacteriol., 97, 1184-1191.

Martinez, E., Palacios, R., and Sanchez, F. (1987) Nitrogen-fixing nodules induced by Agrobacterium tumefaciens harboring Rhizobium phaseoli plasmids. J. Bacteriol., 169, 2828-2834.

Novikova, N. and Safronova, V. (1992) Transconjugants of Agrobacterium radiobacter harboring Sym genes of Rhizobium galegae can form an effective symbiosis with Medicago sativa. FEMS Microbiol. Lett., 93, 261-268.

Reed, K. C. and Mann, D. A. (1985) Rapid transfer of DNA from agarose gels to nylon membranes. Nucleic. Acids. Res., 13, 7207-7221.

Sambrook, J., Fritsch, E. F., and Maniatis, T. (1989) Molecular Cloning: A Laboratory Manual, 2nd ed., Cold Spring Harbor, N.Y., p. A-1.

Sawada, H., leki, H., Oyaizu, H., and Matsumoto, S. (1993) Proposal for rejection of Agrobacterium tumefaciens and revised descriptions for the genus Agrobacterium and for Agrobacterium radiobacter and Agrobacterium rhizogenes. Int. J. Syst. Bacteriol., 43, 694-702.

Sherwood, M. T. (1970) Improved synthetic medium for the growth of Rhizobium. J. Appl. Bacteriol., 33, 708-713.

Simon, R. (1984) High frequency mobilization of Gram-negative bacterial replicons by the in vitro constructed Tn5-mob transposon. Mol. Gen. Genet., 196, 413-420.

Spaink, H. P. (1995) The molecular basis of infection and nodulation by Rhizobia: The ins and outs of sympathogenesis. Annu. Rev. Phytopathol., 33, 345-368.

Truchet, G., Rosenberg, C., Vasse, J., Julliot, S., Camut, S., and Denarie, J. (1984) Transfer of Rhizobium meliloti pSym genes into Agrobacterium tumefaciens host-specific nodulation by atypical infection. J. Bacteriol., 157, 134-142.

Uchiumi, T., Higashi, S., and Abe, M. (1995) Nodule formation by clover-Rhizobium carrying chromosomal nod genes. J. Gen. Appl. Microbiol., 41, 11-22.

Ueda, T., Suga, Y., Yahiro, N., and Matsuguti, T. (1995) Phylogeny of Sym plasmids of rhizobia by PCR-based sequencing of a nodC segment. J. Bacteriol., 177, 468-472.

Watson, B., Currier, T. C., Gordon, M. P., Chilton, M. D., and Nester, E. W. (1975) Plasmid required for virulence of Agrobacterium tumefaciens. J. Bacteriol., 123, 255-264.

Wong, C. H., Pankhurst, C. E., Kondorosi, A., and Broughton, W. J. (1983) Morphology of root nodules and nodule-like structures formed by Rhizobium and Agrobacterium strains containing a Rhizobium meliloti megaplasmid. J. Cell Biol., 97, 787-794. 